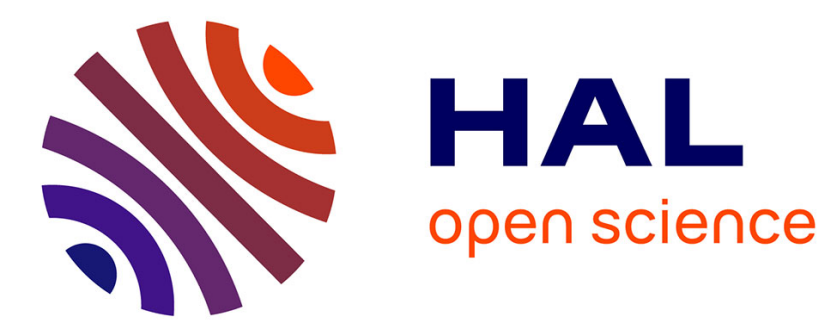

\title{
Reliability Estimation by ALT when no Analytical Model Holds
}

Pascal Lantieri, Fabrice Guerin, Ridha Hamblia

\section{To cite this version:}

Pascal Lantieri, Fabrice Guerin, Ridha Hamblia. Reliability Estimation by ALT when no Analytical Model Holds. Quality and Reliability Engineering International, 2010, 26 (6), pp.521-641. 10.1002 /qre. 1085 . hal-00881695

\section{HAL Id: hal-00881695 https://hal.science/hal-00881695}

Submitted on 8 Nov 2013

HAL is a multi-disciplinary open access archive for the deposit and dissemination of scientific research documents, whether they are published or not. The documents may come from teaching and research institutions in France or abroad, or from public or private research centers.
L'archive ouverte pluridisciplinaire HAL, est destinée au dépôt et à la diffusion de documents scientifiques de niveau recherche, publiés ou non, émanant des établissements d'enseignement et de recherche français ou étrangers, des laboratoires publics ou privés. 


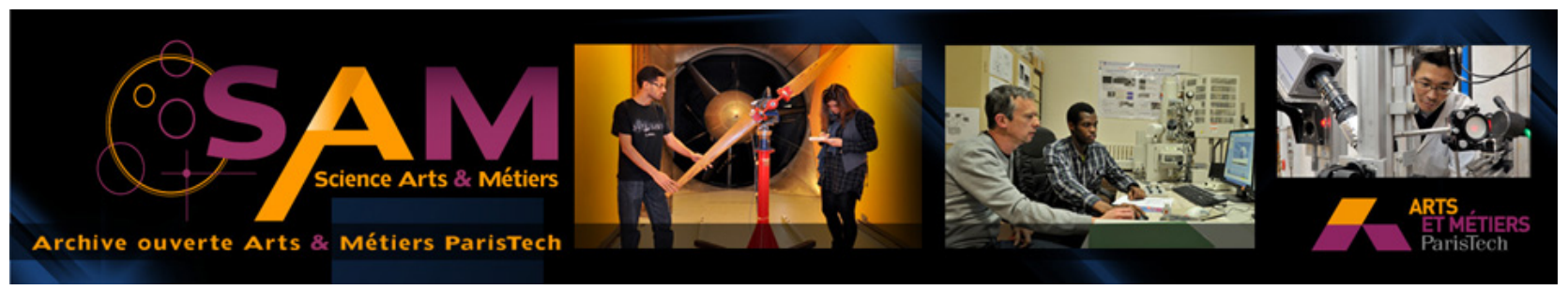

Science Arts \& Métiers (SAM)

is an open access repository that collects the work of Arts et Métiers ParisTech researchers and makes it freely available over the web where possible.

This is an author-deposited version published in: http://sam.ensam.eu

Handle ID: .http://hdl.handle.net/10985/7481

\section{To cite this version :}

Pascal LANTIERI, Fabrice GUERIN, Ridha HAMBLIA - Reliability Estimation by ALT when no Analytical Model Holds - Quality and Reliability Engineering International - Vol. 26, $n^{\circ} 6$, p.521-641 - 2010 


\title{
Reliability Estimation by ALT when no Analytical Model Holds
}

\author{
P. Lantiéri, ${ }^{a * \dagger}$ F. Guérin ${ }^{b}$ and R. Hamblic
}

This paper presents an accelerated life testing method applicable to devices or systems when no analytical relationship with respect to the stress level can be defined. If a numerical approach remains possible, the numerical model can be fitted to the accelerated test results. Thus, long-term failures can be predicted from short tests. This method is carried out in the case of fatigue, the evolution of the damage leading to the failure having to be modeled by a numerical finite element method. Copyright $\odot 2010$ John Wiley \& Sons, Ltd.

Keywords: accelerated life testing; design of experiments; finite element model; numerical methods; fatigue

\section{Introduction}

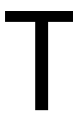

he evolution of industrial competition requires estimating the reliability levels at normal operating condition as quickly as possible. These estimations may be obtained from accelerated life test (ALT). It consists of testing a sample at stress levels $\left(S_{1}, S_{2}, \ldots\right)$ higher than the normal one $S_{0}$ and extrapolating the lifetime distribution obtained at the normal level (Figure 1).

A so-called acceleration model defines a specific lifetime $v$ with respect to the stress level $S$. For basic components, the lifetime of any unit at a given stress level often follows a Weibull or lognormal distribution with a constant shape parameter for any level $S$ and the acceleration model is log-linear ${ }^{1,2}$, that is:

$$
v(S)=\mathrm{e}^{\beta^{\top} \cdot Z(S)}
$$

where $Z(S)$ is a basis of known functions of $S$ and $T$ denotes the transposition operator.

These models are not suitable for complex devices but other researchers have extended ALT methods to these products ${ }^{3-6}$.

The method presented in this paper consists of fitting a numerical model to experimental specific lifetimes from ALT. As the usual iterating methods to minimize the fitting error are not easily applicable for numerical models, we suggest approximating this error by a polynomial function of the second degree.

This approximation can be obtained from discrete estimates of the error for several lists of parameter values. To do this, it may be appropriate to define a central composite design (CCD) in the sharpest possible domain. Then, the model can be fitted by minimizing the approximating function.

\section{Fitting of the acceleration model}

\subsection{Inverse method used}

Let us consider a vector $\beta$ of $p$ parameters for the acceleration model and the corresponding list of specific lifetimes $v\left(S_{i}\right)$.

In a direct problem, $\beta$ would be known and the times $v\left(S_{i}\right)$ would have to be estimated. Let us note $F$ the corresponding operator. Even without any analytic expression of $F$, it may be defined by an iterative process.

In an inverse problem, the experimental values of $v\left(S_{i}\right)$ are given and the corresponding components of $\beta$ have to be estimated. If the operator $F$ is bijective and if the experimental data are precise, one only has to calculate the inverse $F^{-1}$ (Figure 2 ).

\footnotetext{
${ }^{a}$ Arts and Metiers ParisTech (LPMI), 2 bld du Ronceray, 49035 Angers Cedex 01, France

${ }^{b}$ University of Angers (LASQUO), 62 av. ND du Lac, 49000 Angers, France

'Polytech'Orléans (LMSP), 8 rue Léonard de Vinci, 45072 Orléans Cedex 2, France

*Correspondence to: P. Lantiéri, Arts and Metiers ParisTech (LPMI), 2 bld du Ronceray, 49035 Angers Cedex 01, France.

${ }^{\dagger}$ E-mail: pascal.lantieri@angers.ensam.fr
} 


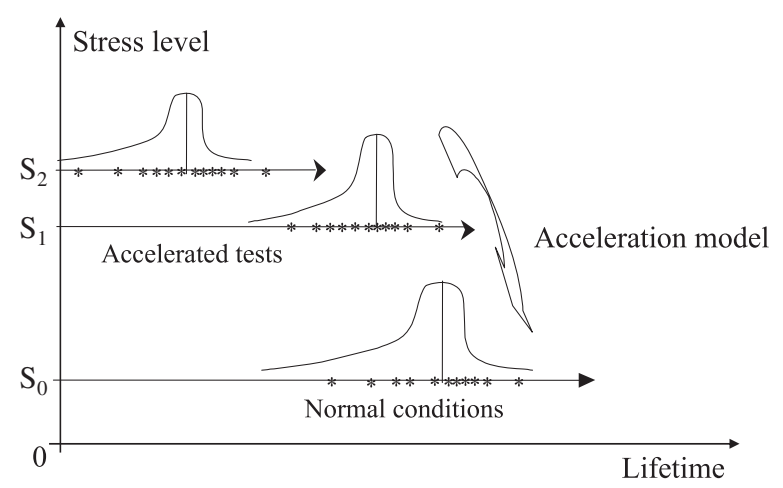

Figure 1. Lifetime estimation with ALT

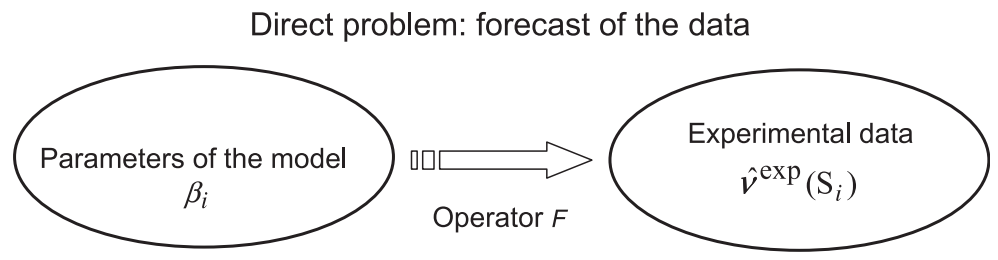

Inverse problem: estimation of the parameters

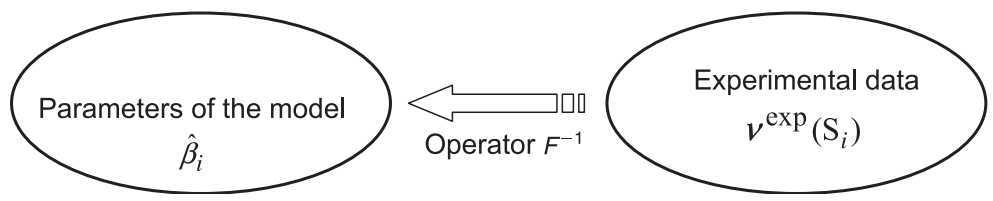

Figure 2. Direct and inverse problems

However, the list of data may include noise and the number of experimental values $v^{\exp }\left(S_{i}\right)$ may be different from the number of parameters. Then, $\beta$ can be estimated by solving the optimization problem:

$$
\begin{aligned}
& \phi(\hat{\beta})=\operatorname{Min}_{\beta \in \mathbb{R}^{p}} \phi(\beta) \\
& \phi(\beta)=\| F(\beta)-v^{\exp \left(\mathscr{S}_{A L T}\right) \|}
\end{aligned}
$$

where $p$ is the number of parameters for the acceleration model and where $\mathbb{R}^{p}$ denotes all the lists of $p$ reals.

The algorithm used to estimate the model's parameters is illustrated in Appendix A and detailed in the following.

\subsection{Minimization of the error $\phi$}

For analytic expressions of $\phi$, the previous problem can be solved by several processes, such as the Newton or Gradient methods. However, these methods are difficult to apply for numerical models.

To face this problem, $\phi$ may be approximated by a polynomial regression $\tilde{\phi}$ of a list $\left\{\left(\beta^{(k)}, \phi\left(\beta^{(k)}\right)\right), k \in[1, K]\right\}$, where $K$ is an integer greater than the length of the polynomial, the vectors $\beta^{(k)}$ are chosen in a domain $\mathscr{D}_{\beta}$ of possible values for $\beta$.

To ensure one single minimum, $\tilde{\phi}$ should be a polynomial function of the second degree.

$\mathscr{D}_{\beta}$ can be centered at a prior estimate $\hat{\beta}^{p r}$ of the vector $\beta$, from bibliography or previous tests on similar products. The bounds may be defined from the uncertainties $\delta \beta_{i}$ on the prior estimates $\hat{\beta}_{i}^{p r}$.

To obtain a quadratic response surface, the list of points $\beta^{(k)}$ must be defined according to a Box-Wilson $\mathrm{CCD}^{7}$ in $\mathscr{D}_{\beta}$. If normalized variables $\beta_{i}^{*}=\left(\beta_{i}-\beta_{i}^{*}\right) / \delta \beta_{i}$ are used, the CCD is defined by the points $\beta^{(k)}$ located at:

- the corners of the hypercube $[-1,1]^{p}$,

- its center $0_{\mathbb{R}^{p}}$,

- $2 p$ star points located on the natural axes of $\mathbb{R}^{p}$ at the values $+\delta$ and $-\delta$, with $\delta=2^{p / 4}$ to ensure the isovariance of the design of experiments (DoE) by rotation. 
For any $\beta^{(k)}$, the list of specific lifetimes'estimates $\hat{v}\left(\mathscr{S}_{A L T}\right)$ can be obtained by the numerical model, and the fitting errors $y_{k}=\phi\left(\beta^{(k)}\right)$ can be calculated. Then, the list of coefficients $\Theta$ of the polynomial function $\tilde{\phi}$ is estimated by solving the inconsistent system of equations:

$$
Y=\Theta \cdot X
$$

where $Y$ is the response vector with components $y_{k}$ and $X$ is the matrix defined at any column $k$ by:

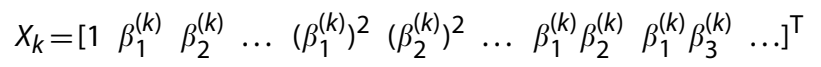

It leads to the vector of coefficients' estimates:

$$
\hat{\Theta}=\left(X^{\top} \cdot X\right)^{-1} \cdot X^{\top} \cdot Y
$$

To eliminate the factors due to the random effects generated by the fitting method, an analysis of variance can be carried out for each term of the polynomial function $\tilde{\phi}^{7,8}$. Thus, an second approximating polynomial function with coefficients significantly different from zero (at a confidence level usually equal to 95\%) can be defined. This process is repeated until all the coefficients are proved to be significant.

The resulting polynomial function $\tilde{\tilde{\phi}}$ can be considered as a correct approximation of the error $\phi$, and thus, the solution of the problem (3) can be approximated by minimizing $\tilde{\tilde{\phi}}(\beta)$. The estimate $\hat{\beta}$ can be given by solving $\nabla \tilde{\tilde{\phi}}(\beta)=0$ for example.

\subsection{Goodness-of-fit of the numerical model defined}

To verify the goodness-of-fit of the solution $\hat{\beta}$, the assumption $\phi(\hat{\beta})=0$ must be tested by a one-sided test (for a given risk $\alpha$ ). For a constant standard deviation $\sigma$ at any level $S_{i}$ and if $v$ denotes a mean, the central limit theorem states that all the terms of $\phi(\beta)^{2} / \sigma^{2}$ are (asymptotically) squares of normal standard variables. Thus, by definition, this sum follows a $\chi^{2}$ distribution with $I$ degrees of freedom, even if the number of levels $I$ is low.

Then, if $\left(\phi(\hat{\beta})^{2} / \sigma^{2}\right)<\chi_{1-\alpha, l}^{2}$, it means that the fitting error is not significant and the numerical model defined with $\hat{\beta}$ cannot be rejected. Otherwise, the model defined with $\hat{\beta}$ must be rejected and another polynomial function $\tilde{\tilde{\phi}}$ has to be defined to obtain another estimate of $\beta$ in the same way.

\section{Application to fatigue ALT on paper clips}

\subsection{Experiment}

From torsion fatigue tests with an opening angle $\alpha$ successively equal to $90^{\circ}$ and $180^{\circ}$, a lifetime distribution can be predicted for a normal opening angle $\alpha=45^{\circ}$ (Figures 3-5). As $\alpha$ is the parameter leading to the acceleration of failures, it can be considered as the stress $S$ defined in Figure 1. As the opening frequency is constant, the lifetime of any unit is given by the number of cycles to failure $n$ and $v$ can be the median fatigue lifetime. It means that the ALT is defined for the levels $S_{1}=90^{\circ}, S_{2}=180^{\circ}$ and $v$ has to be estimated at the level $S_{0}=45^{\circ}$ by a fitted finite element model (FEM).

For any level $S_{i}(i \in[0,2])$, the experimental lifetimes obtained are given in Appendix $C$ (only their integer parts, knowing that the experimental conditions are very approximative).

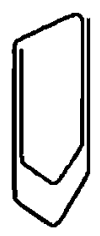

Figure 3. Paper clip (initial state)

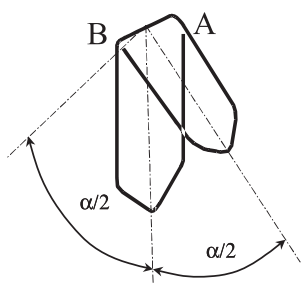




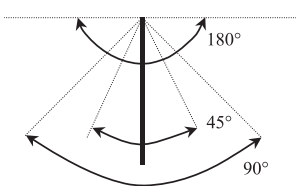

Figure 5. The 3 levels

\subsection{Definition of the model}

In the case of fatigue, the most significant and simple data available to define the acceleration model are the median fatigue lifetimes $N\left(S_{i}\right)$. It could be defined with respect to $\alpha$ by an inverse power law, but for such a complex case, this model would be very inaccurate. An alternative method consists of using a damaging model. For a constant strain amplitude, the damage increases from a given increment at each cycle and it can be assumed that the failure occurs as soon as the damage equals to 1 . Thus, for any level $S_{i}$ :

$$
\hat{N}\left(S_{i}\right)=\frac{1}{\hat{D}_{\max }}
$$

where $\hat{D}_{\max }$ is the maximum damage in the paper clip estimated by FEM for one cycle.

To estimate the damages, the paper clip has been meshed into 5222 3D-elements, the nodes of the central part $A B$ (Figure 4) have been assumed motionless and, for each level, the cycle has been divided into $N_{t}=120$ rotations on one side with an angle $\alpha / N_{t}$, with $2 N_{t}$ other rotations in the other direction and with $N_{t}$ new rotations to go back to the initial position.

Let us note that $\varepsilon\left(j, n_{t}\right)$ and $\sigma\left(j, n_{t}\right)$ are the strain and stress tensors at the node $j$ and at the time increment $n_{t}, \varepsilon_{p l}\left(j, n_{t}\right)$ the plastic part of the whole strain $\varepsilon\left(j, n_{t}\right), \sigma_{e q}\left(j, n_{t}\right)$ the Von Mises equivalent stress at the node $j$ and at the time increment $n_{t}, \varepsilon_{e q}\left(j, n_{t}\right)$ the equivalent strain at the node $j$ and at the time increment $n_{t}, C_{e l}$ the Hooke elastic operator, $\sigma_{0}$ the yield stress (obtained by a tensile test), and $K$ and $m$ the parameters of the non linear hardening law, where the equivalent strain and stress are defined by $\sqrt{\sum \lambda_{i}^{2}}$, the $\lambda_{i}$ denoting the eigenvalues of these tensors, the so-called hardening law states that the increase of $\sigma$ due to a plastic strain $\varepsilon_{p l}$ is given by $\delta \sigma=K \varepsilon_{p l}^{m}$.

The damage at any point $j$ is given by Bathias and Baillon?

$$
D(j)=D_{1}(j)+D_{2}(j)
$$

where

- $D_{1}(j)=\beta_{1} \cdot \varepsilon_{p l}(j)$ is the damage due to cyclic hardening at the node $j$,

- $D_{2}(j)=\varepsilon_{p l}(j)^{\beta_{3}} / \beta_{2}$ is the low cycle fatigue damage at the node $j$,

$\left\{\beta_{i}, i \in[1, p]\right\}$ being the list of the model's parameters to estimate.

Moreover, as the distribution of fatigue lifetime is lognormal (with the same standard deviation at any level), the specific parameter $v$ should be $\log (N)$.

Then, the direct problem illustrated in Figure 2 can be defined with:

- $\beta=\left\{\beta_{1}, \beta_{2}, \beta_{3}\right\}^{\top}$,

- $v^{\exp }\left(\mathscr{S}_{A L T}\right)=\left\{v^{\exp }\left(90^{\circ}\right), v^{\exp }\left(180^{\circ}\right)\right\}$

The operator $F$ mentioned in Figure 2 is defined by the following process ${ }^{10-12}$ :

- Initialization of the FEM $\left(n_{t}=0\right)$ : paper clip closed. At any point $j$ of the mesh: $\varepsilon\left(j, n_{t}\right)=\sigma\left(j, n_{t}\right)=[0]$ and $D(j)=D_{1}(j)=D_{2}(j)=0$.

- At the end of any opening or closing increment, $\varepsilon\left(j, n_{t}\right)$ is estimated ${ }^{13-15}$ for any $j$. It leads to a prediction of $\sigma_{e q}\left(j, n_{t}\right)$ based on a purely elastic strain assumption:

$$
\sigma^{*}\left(j, n_{t}\right)=(1-D) C_{e l}\left[\varepsilon\left(j, n_{t}\right)-\varepsilon_{p l}\left(j, n_{t}-1\right)\right]
$$

- At any point $j$, the Von Mises yield function, $f=\sigma_{e q}\left(j, n_{t}\right)-(1-D)\left(\sigma_{0}+K \varepsilon_{p l}\left(j, n_{t}\right)\right)$, is calculated under the elasticity assumption, that is with $\sigma_{e q}=\sigma^{*}$.

If $f \leqslant 0$, the elasticity assumption is acceptable and $\sigma\left(j, n_{t}\right)=\sigma^{*}\left(j, n_{t}\right)$.

Otherwise, a plastic correction is given.

- $D_{1}(j), D_{2}(j)$ and $D(j)$ are modified for every nodes and the process goes back to step 2 (until the opening/closing cycle is ended)

- Then, the maximum damage within every nodes and Relationship (6) lead to the estimate $\hat{v}\left(S_{i}\right)$ for the opening angle $S_{i}$ chosen.

If this process is carried out for any level $S_{i}$ defining the ALT, any vector of parameters $\beta$ leads to a list of estimations $\hat{v}(\mathscr{S}$ ALT), which defines the operator $F$. 
For the inverse problem, the process detailed in Section 3 leads to $\hat{\beta}$, estimated from the ALT results as follows:

- ALT results given in Appendix B lead to $N^{\exp }(\mathscr{S} A L T)=\{7.2,2.12\}$.

- Tests on similar products lead to:

$\hat{\beta}^{p r}=\{0.5,2.45,0.55\}^{\top}$ with the vector of accuracy levels

$\delta \beta=\{80 \% \times 0.5,50 \% \times 2.45,50 \% \times 0.55\}^{\top}$.

- A CCD is defined in $\mathscr{D}_{\beta}$ for the normalized parameters, $\beta_{i}^{*}=\left(\beta_{i}-\hat{\beta}_{i}^{p r}\right) / \delta \beta_{i}, i \in[1, p]$.

The corresponding 15 points $\beta^{(k)}$, the resulting estimations $\hat{v}\left(\beta^{(k)}\right)$ obtained with ABAQUS and the fitting errors $y_{k}=\phi\left(\beta^{(k)}\right)$ are given in Appendix C.

- The regression on the list $\left\{\left(\beta^{*(k)}, y_{k}\right), k \in[1,15]\right\}$ leads, with a determination parameter $R^{2}=0.94$, to the approximation of the error:

$$
\begin{aligned}
\tilde{\phi}(\beta)= & 1.28+0.23 \beta_{1}^{*}-0.43 \beta_{2}^{*}-3.02 \beta_{3}^{*}+0.14\left(\beta_{1}^{*}\right)^{2}+0.087\left(\beta_{2}^{*}\right)^{2} \\
& +2.79\left(\beta_{3}^{*}\right)^{2}-0.018 \beta_{1}^{*} \cdot \beta_{2}^{*}-0.586 \beta_{1}^{*} \cdot \beta_{3}^{*}+0.077 \beta_{2}^{*} \beta_{3}^{*}
\end{aligned}
$$

- Student tests prove that the four terms in $\beta_{1}^{*},\left(\beta_{1}^{*}\right)^{2}, \beta_{1}^{*} \cdot \beta_{2}^{*}$ and $\beta_{2}^{*} \cdot \beta_{3}^{*}$ are not significant.

- As the elimination of the term in $\left(\beta_{1}^{*}\right)^{2}$ does not ensure a minimum anymore, it is kept in a first time. The other three are eliminated. In this new basis, the polynomial fit is defined, with a determination parameter slightly different $\left(R^{2}=0.92\right)$, by:

$$
\tilde{\tilde{\phi}}(\beta)=1.35-0.43 \beta_{2}^{*}-3.09 \beta_{3}^{*}+0.26\left(\beta_{1}^{*}\right)^{2}+0.09\left(\beta_{2}^{*}\right)^{2}+2.97\left(\beta_{3}^{*}\right)^{2}-0.46 \beta_{1}^{*} \beta_{3}^{*}
$$

- A conjugate gradient method leads to the minimum of $\tilde{\tilde{\phi}}$ for the parameters' values, $\hat{\beta}_{1}=0.49, \hat{\beta}_{2}=2.39$ and $\hat{\beta}_{3}=0.56$.

- With these estimates, the process defined for the direct problem leads to $\hat{v}\left(\mathscr{S}_{A L T}\right)=\{2.10,0.83\}$, whereas the experimental values are 1.70 and 1.34. A length of 50 paper clips is high enough to assume that the mean estimates follow normal distributions. The constant standard deviation ${ }^{16}$ can be estimated at $\hat{s}=0.30$. It can be seen that

$$
\sum\left(\frac{\hat{v}\left(S_{i}\right)-v^{\exp }\left(S_{i}\right)}{\hat{s}}\right)^{2}=4.56
$$

whereas $\chi_{2,0.05}^{2}=5.99$.

It shows that these errors are not significant at a risk $\alpha=5 \%$.

Then, the numerical model can be assumed fitted. The process detailed for the direct problem leads to the damages and the deformed shape shown in Figure 6. It leads to: $\hat{v}_{F}\left(S_{0}\right)=2.43$, that is $\mathrm{e}^{2.43}=11.4$ cycles.

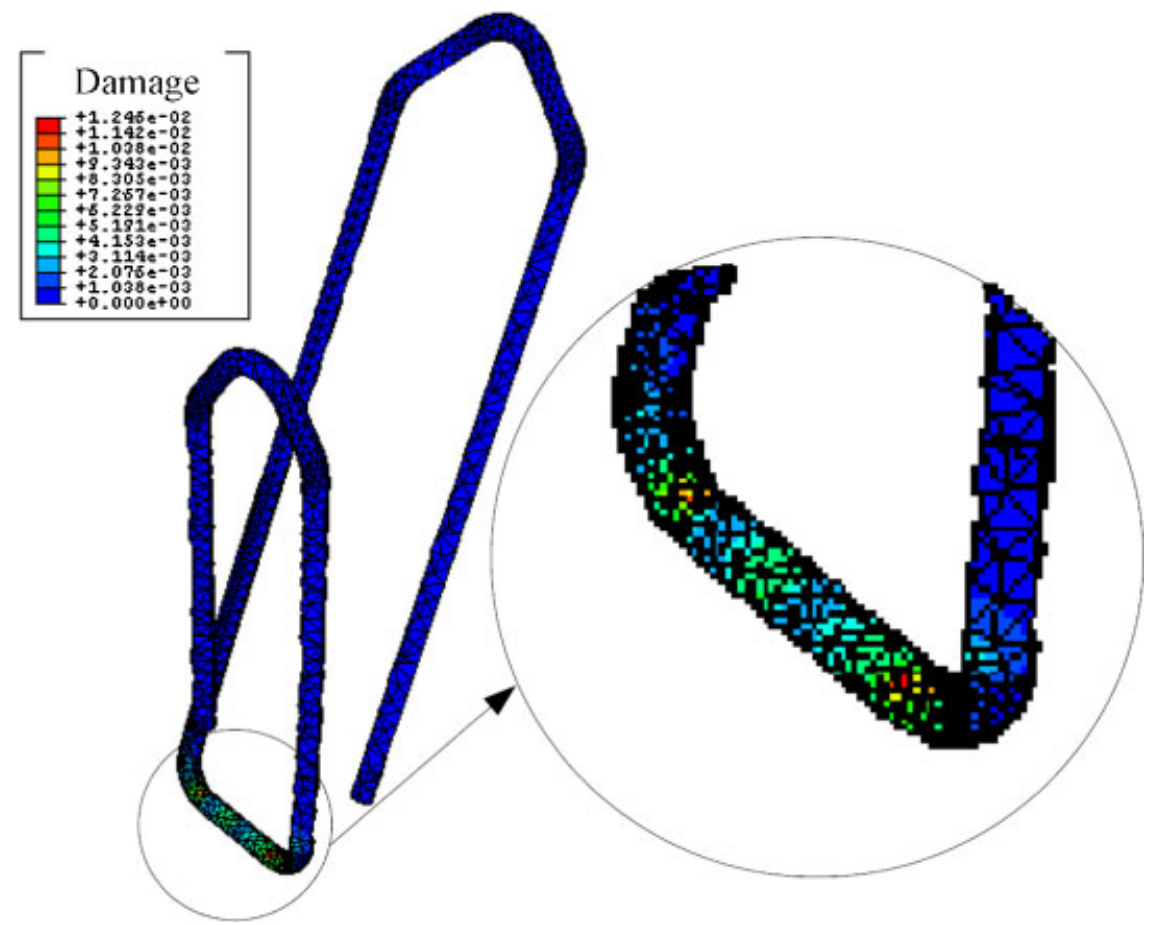

Figure 6. Damage after 1 opening cycle 


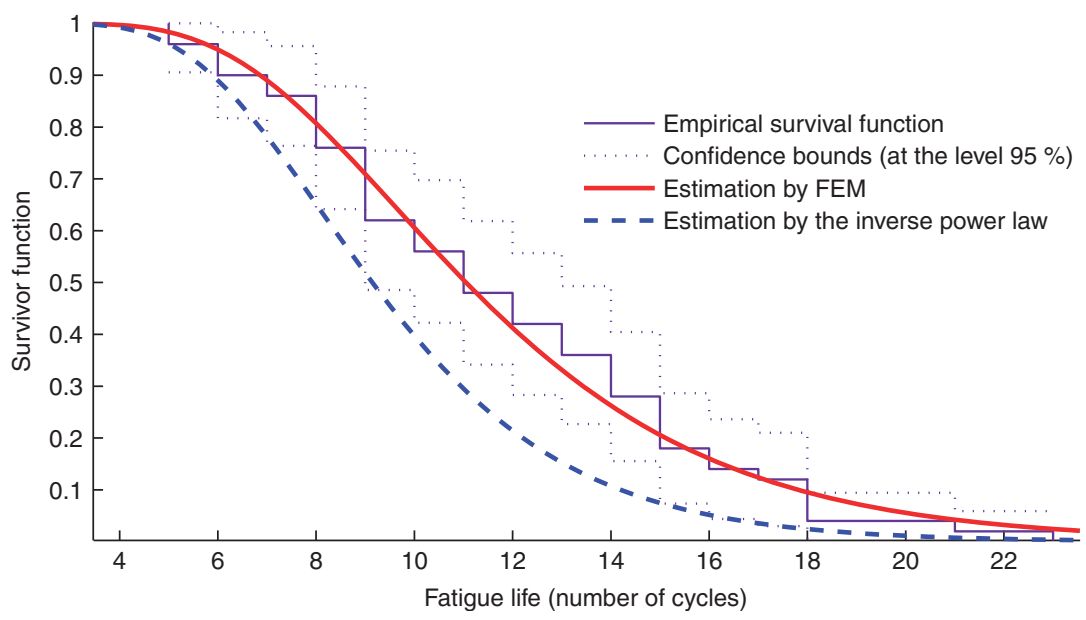

Figure 7. Experimental and estimated survivor functions

The estimate obtained from ALT can be verified by experiment. Tests on 50 paper clips with a normal opening angle have led to a mean of 11.8 cycles (Appendix B), that is to $v^{\exp }\left(S_{0}\right)=2.41$, whereas the inverse power model would have led to $\hat{v}\left(S_{0}\right)=2.06$, that is to a mean fatigue life of 10.7 cycles.

It can be seen in Figure 7 that, at a risk $\alpha=5 \%$, the inverse power model would not have led to a lognormal distribution consistent with the empirical one, whereas the estimation obtained by FEM is acceptable, the empirical survival function and its bounds being estimated by the Kaplan Meier method.

\section{Conclusion and work-in-progress}

By calculating the materials' parameters so that the fatigue lifetimes estimated by FEM fit the ALT results, it is possible to quickly predict for any component or device a long-term reliability.

A numerical DoE has to be defined and the errors with experimental results obtained for the different points of the DoE have to be fitted by a polynomial function. It leads to fit the FEM by minimizing this polynomial.

The process has been illustrated for fatigue on paper clips but it would be worth using it for other fatigue mechanisms, eventually coupled with other kinds of damage (wear, corrosion, thermal fatigue, etc.), on whole mechanical devices. To do this, the optimization process used to minimize the error could be improved.

\section{Acknowledgements}

The authors would like to thank D. Lepadatu for his help in fitting the finite element model with the central composite DoE.

\section{References}

1. Nelson W. Accelerated Testing: Statistical Models, Test Plans and Data Analysis (Wiley Series in Probability and Mathematical Statistics). Wiley: U.S.A., 1990.

2. Bagdonavicius V, Nikulin M. Accelerated Life Models. Chapman \& Hall/CRC: U.S.A., 2002.

3. Om Prakash Y, Nipun C, Canan B. Complex system reliability estimation methodology in the absence of failure data. Quality and Reliability Engineering International 2008; 24(7):745-764.

4. Upadhyayula K, Dasgupta A. Physics-of-failure guidelines for accelerated qualification of electronic systems. Quality and Reliability Engineering International 1998; 14(6):433-447.

5. Liao H, Elsayed EA. Reliability inference for field conditions from accelerated degradation testing. Naval Research Logistics 2006; 53(6): 576-587.

6. Yang K, Yang G. Robust reliability design using environmental stress testing. Quality and Reliability Engineering International 1998; 4(6): 409-416.

7. Box G, Wilson K. On the experimental attainment of optimum conditions. Journal of the Royal Statistical Society, Series B 1951; 13:1-45.

8. Cornell JA. How to Apply Response Surface Methodology. ASQ Quality Press, 1990. ISBN: 0873890663.

9. Bathias C, Baïlon JP. La fatigue des matériaux et des structures. Hermes: France, 1997.

10. Chaboche J. Continuous damage mechanics-A tool to describe phenomena before crack initiation. Nuclear Engineering and Design 1981; 64:233-247. 
11. Gurson AL. Continuum theory of ductile rupture by void nucleation and growth. Journal of Engineering Materials and Technology 1977; 99:2-15.

12. Lemaitre J. A continuous damage mechanics model for ductile fracture. Journal of Engineering Materials and Technology 1985; 107:83-89.

13. Wilson FW. Die Design Handbook. American Society of Tool and Manufacturing Engineers: U.S.A., 1965.

14. Sidebottom O, Gebbhardt C. Elastic springback in plates and beams formed by bending. Experimental Mechanics 1979; 19:371-377. DOI: 10.1007/BF02324252.

15. ABAQUS. HKS Theory Manual-Version 6.4. 2003.

16. Guérin F, Hambli R. Standard accelerated life testing model applied to mechanical components. Journal of IEST 48(1):103-113.

\section{Notations}

$\beta \quad$ vector of parameters for the acceleration model

$p \quad$ number of parameters for the acceleration model

I number of stress levels for the ALT

$S_{i} \quad$ stress levels for the ALT $(i \in[1, I])$

$\mathscr{S}_{\text {ALT }} \quad$ list of the stress levels $S_{i}$ defined for the ALT

$v(S)$ : $\quad$ specific lifetime of the tested product at the constant stress level $S$

$v^{\exp }(S) \quad$ experimental value of $v(S)$

$\hat{v}(S) \quad$ estimate of $v(S)$ from the current numerical model

$\hat{v}_{F}(S) \quad$ estimate of $v(S)$ from the fitted numerical model

$\phi(\beta) \quad$ fitting error between the experimental values of $v\left(S_{i}\right)$ and their estimates from the numerical model $\left(\phi(\beta)=\left[\sum_{S_{i} \in \mathscr{S}_{A L T}}\left(v^{\exp }\left(S_{i}\right)-\hat{v}\left(S_{i}\right)\right)^{2}\right]^{1 / 2}\right)$

$\tilde{\phi}(\beta) \quad$ polynomial of the second degree approximating the error $\phi$ (in a least-square sense)

$\tilde{\tilde{\phi}}(\beta) \quad$ simplified polynomial approximating the error after elimination of non significant terms of $\tilde{\phi}(\beta)$

\section{Appendix A: Algorithm of the method}

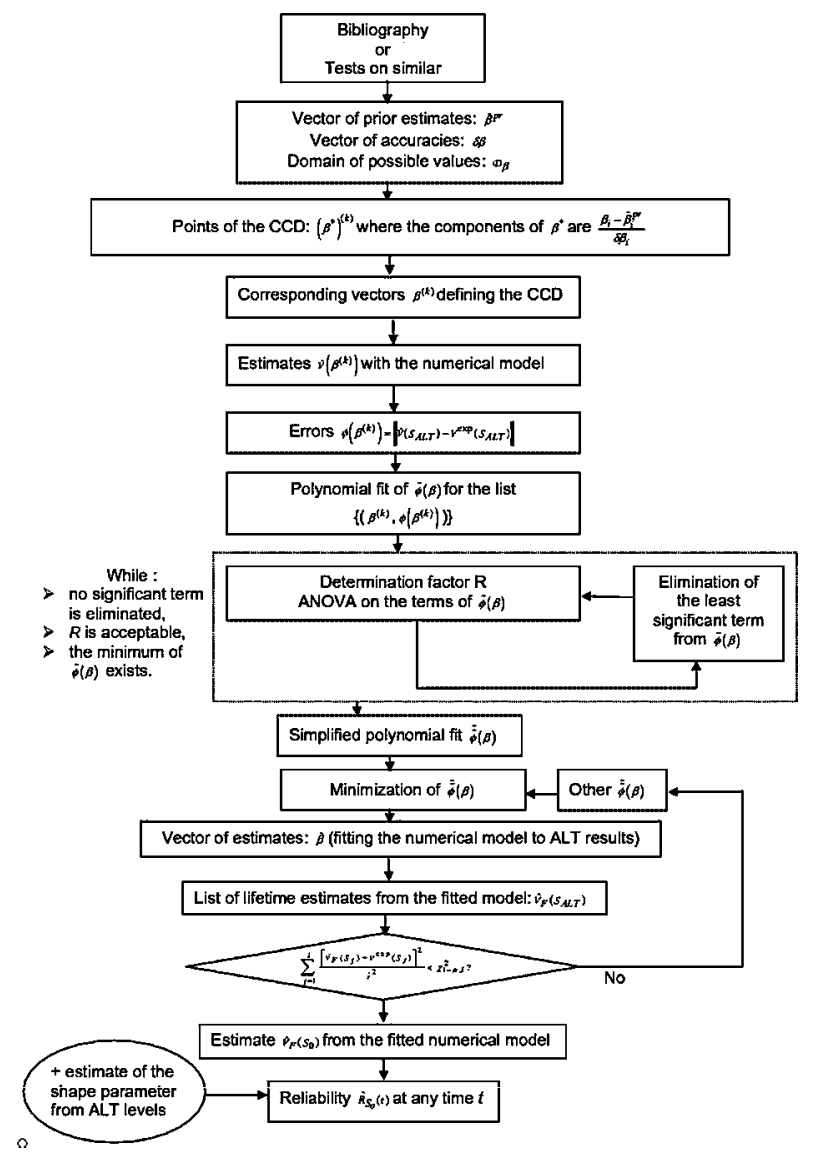


Appendix B: Experimental lifetimes for $\alpha=90^{\circ}, 180^{\circ}$ and $45^{\circ}$ (normal level)

\begin{tabular}{lccccc}
\hline$n_{j}\left(45^{\circ}\right)$ & $n_{j}\left(90^{\circ}\right)$ & $n_{j}\left(180^{\circ}\right)$ & $n_{j}\left(45^{\circ}\right)$ & $n_{j}\left(90^{\circ}\right)$ & $n_{j}\left(180^{\circ}\right)$ \\
\hline 5 & 3 & 2 & 12 & 7 & 5 \\
5 & 4 & 2 & 12 & 7 & 5 \\
6 & 4 & 2 & 12 & 7 & 5 \\
6 & 4 & 2 & 13 & 7 & 5 \\
6 & 4 & 2 & 13 & 7 & 6 \\
7 & 5 & 4 & 13 & 8 & 6 \\
7 & 5 & 4 & 14 & 8 & 6 \\
8 & 5 & 4 & 14 & 8 & 6 \\
8 & 5 & 4 & 14 & 8 & 6 \\
8 & 5 & 4 & 14 & 8 & 6 \\
8 & 5 & 4 & 15 & 8 & 6 \\
8 & 6 & 4 & 15 & 8 & 6 \\
9 & 6 & 4 & 15 & 8 & 6 \\
9 & 6 & 4 & 15 & 8 & 6 \\
9 & 6 & 4 & 15 & 9 & 6 \\
9 & 6 & 4 & 16 & 9 & 7 \\
9 & 6 & 4 & 16 & 9 & 7 \\
9 & 6 & 4 & 17 & 10 & 7 \\
9 & 6 & 5 & 18 & 11 & 7 \\
10 & 6 & 5 & 18 & 11 & 8 \\
10 & 6 & 5 & 18 & 12 & 8 \\
10 & 6 & 5 & 21 & 11 & \\
11 & 6 & 5 & 23 & 13 & \\
11 & 7 & 5 & & 13 & \\
11 & 7 & 5 & & & \\
11 & 7 & 5 & & & \\
\hline
\end{tabular}

\section{Appendix C: Median lifetimes estimated by FEM and fitting errors}

In the case of the test on the paper clips, the fitting error is given for any point $(k)$ of the DoE, by:

$$
\phi\left(\beta^{(k)}\right)=\left[\left(v^{\exp }\left(S_{1}\right)-\hat{v}^{(k)}\left(S_{1}\right)\right)^{2}+\left(v^{\exp }\left(S_{2}\right)-\hat{v}^{(k)}\left(S_{2}\right)\right)^{2}\right]^{1 / 2}
$$

where $v$ denotes $\log (N), N$ being the median lifetime and $\hat{N}^{(k)}\left(S_{i}\right)$ its estimate by FEM at the level $S_{i}$ for the list of parameters $\beta^{(k)}$, and with $v^{\exp }\left(S_{1}\right)=\log (7.2)$ and $v^{\exp }\left(S_{2}\right)=\log (2.12)$.

It leads to the following table.

\begin{tabular}{|c|c|c|c|c|c|c|c|c|}
\hline \multirow[b]{2}{*}{$k$} & \multirow[b]{2}{*}{$\beta^{*(k)}$} & \multirow[b]{2}{*}{$\beta^{(k)}$} & \multicolumn{2}{|c|}{ Level $S_{1}$} & \multicolumn{2}{|c|}{ Level $S_{2}$} & \multirow[b]{2}{*}{$\phi\left(\beta^{(k)}\right)$} & \multirow[b]{2}{*}{ Approximations $\phi\left(\beta^{(k)}\right)$} \\
\hline & & & $D(\%)$ & $N\left(S_{1}\right)$ & $D(\%)$ & $N\left(S_{1}\right)$ & & \\
\hline 1 & $(-1,-1,-1)$ & $(0.26,1.7,0.4)$ & 14.2 & 7.02 & 53.4 & 1.87 & 0.11 & 0.09 \\
\hline 2 & $(-1,-1,1)$ & $(0.26,1.7,0.7)$ & 13.4 & 7.45 & 42.3 & 2.36 & 0.1 & 0.1 \\
\hline 3 & $(-1,1,-1)$ & $(0.26,3.2,0.4)$ & 14.2 & 7.04 & 54.8 & 1.82 & 0.13 & 0.12 \\
\hline 4 & $(-1,1,1)$ & $(0.26,3.2,0.7)$ & 13.3 & 7.5 & 41.0 & 2.44 & 0.17 & 0.16 \\
\hline 5 & $(1,-1,-1)$ & $(0.74,1.7,0.4)$ & 14.4 & 6.95 & 53.5 & 1.87 & 0.16 & 0.14 \\
\hline 6 & $(1,-1,1)$ & $(0.74,1.7,0.7)$ & 13.6 & 7.36 & 42.4 & 2.36 & 0.07 & 0.06 \\
\hline 7 & $(1,1,-1)$ & $(0.74,3.2,0.4)$ & 14.4 & 6.96 & 54.9 & 1.82 & 0.17 & 0.16 \\
\hline 8 & $(1,1,1)$ & $(0.74,3.2,0.7)$ & 13.4 & 7.45 & 41.9 & 2.38 & 0.11 & 0.12 \\
\hline 9 & $(0,0,0)$ & $(0.5,2.45,0.55)$ & 13.8 & 7.23 & 45.8 & 2.18 & 0.00 & 0.00 \\
\hline 10 & $(-d, 0,0)$ & $(0.1,2.45,0.55)$ & 13.7 & 7.29 & 45.8 & 2.19 & 0.01 & 0.02 \\
\hline 11 & $(d, 0,0)$ & $(0.9,2.45,0.55)$ & 14.0 & 7.16 & 45.9 & 2.18 & 0.01 & 0.02 \\
\hline 12 & $(0,-d, 0)$ & $(0.5,1.2,0.55)$ & 13.5 & 7.41 & 42.4 & 2.36 & 0.08 & 0.1 \\
\hline 13 & $(0, d, 0)$ & $(0.5,3.7,0.55)$ & 14.5 & 6.9 & 51.8 & 1.93 & 0.16 & 0.17 \\
\hline 14 & $(0,0,-d)$ & $(0.5,2.45,0.8)$ & 14.3 & 6.97 & 54.4 & 1.84 & 0.16 & 0.19 \\
\hline 15 & $(0,0, d)$ & $(0.5,2.45,0.3)$ & 13.3 & 7.49 & 40.9 & 2.45 & 0.16 & 0.16 \\
\hline
\end{tabular}


Authors' biographies

Pascal Lantiéri is Doctor engineer in Mechanics, researcher in the Laboratory of Process and Materials at Arts and Metiers ParisTech (center of Angers, France). His researches are in the area of statistics applied to mechanical or electronic components. $\mathrm{He}$ also teaches mathematics and statistics applied to fatigue or Statistical Process Control to students of mechanical engineering.

Fabrice Guérin is a Professor at the University of Angers. He teaches courses on Mechanical technology, Statistics, Metrology, Reliability, etc. His technical interests lie mainly in mechanical reliability, Bayesian statistics and accelerated testing.

Ridha Hambli is a Professor at Polytech'Orléans. He teaches courses on Mechanical technology, Finite elements methods, etc. His technical interests lie mainly in Finite Elements Models applied to mechanics. 